\title{
Parents' Source of Vaccine Information and Impact on Vaccine Attitudes, Beliefs, and Nonmedical Exemptions
}

\author{
Abbey M. Jones, ${ }^{1}$ Saad B. Omer, ${ }^{2}$ Robert A. Bednarczyk, ${ }^{1}$ Neal A. Halsey, ${ }^{3}$ \\ Lawrence H. Moulton, ${ }^{3}$ and Daniel A. Salmon ${ }^{3}$ \\ ${ }^{1}$ Hubert Department of Global Health, Emory University Rollins School of Public Health, 1518 Clifton Road NE, \\ Atlanta, GA 30322, USA \\ ${ }^{2}$ Hubert Department of Global Health, Emory University Rollins School of Public Health and Emory Vaccine Center, \\ 1518 Clifton Road NE, Atlanta, GA 30322, USA \\ ${ }^{3}$ Department of International Health, Institute for Vaccine Safety, Johns Hopkins Bloomberg School of Public Health, \\ Baltimore, MD 21205, USA
}

Correspondence should be addressed to Saad B. Omer, somer@emory.edu

Received 13 July 2012; Revised 5 September 2012; Accepted 7 September 2012

Academic Editor: John Iskander

Copyright (C) 2012 Abbey M. Jones et al. This is an open access article distributed under the Creative Commons Attribution License, which permits unrestricted use, distribution, and reproduction in any medium, provided the original work is properly cited.

\begin{abstract}
In recent years, use of the Internet to obtain vaccine information has increased. Historical data are necessary to evaluate current vaccine information seeking trends in context. Between 2002 and 2003, surveys were mailed to 1,630 parents of fully vaccinated children and 815 parents of children with at least one vaccine exemption; 56.1\% responded. Respondents were asked about their vaccine information sources, perceptions of these sources accuracy, and their beliefs about vaccination. Parents who did not view their child's healthcare provider as a reliable vaccine information source were more likely to obtain vaccine information using the Internet. Parents who were younger, more highly educated, and opposed to school immunization requirements were more likely than their counterparts to use the Internet for vaccine information. Compared to parents who did not use the Internet for vaccine information, those who sought vaccine information on the Internet were more likely to have lower perceptions of vaccine safety (adjusted odds ratio (aOR), 1.66; 95\% CI, 1.18-2.35), vaccine effectiveness (aOR, 1.83; 95\% CI, 1.32-2.53), and disease susceptibility (aOR, 2.08; 95\% CI, 1.49-2.90) and were more likely to have a child with a nonmedical exemption (aOR 3.53, 95\% CI, 2.61-4.76). These findings provide context to interpret recent vaccine information seeking research.
\end{abstract}

\section{Introduction}

High coverage of recommended vaccines in the United States has resulted in a reduction in incidence of greater than 99\% for many vaccine-preventable diseases [1-3]. These high immunization coverage levels [4] are due, in large part, to school immunization requirements [5]. While immunization coverage is at or near record highs [6], vaccine refusal rates have increased in states that readily allow nonmedical exemptions to school immunization requirements [7]. Additionally, vaccine refusal is often clustered geographically which has been associated with outbreaks of disease [8]. Increasing exemption rates and the potential for reemergence of vaccine-preventable diseases in the United States highlight the need to effectively communicate accurate information on vaccination to parents. The most common source of vaccine information is primary healthcare providers, but research has shown that parents obtain vaccine information from a multitude of other sources as well [9].

The Internet has rapidly become a widely used source of information, including information on vaccines. While Internet use for information seeking is ubiquitous now, it was a common source of health-related information dating back to the early 2000s. In February 2004, it was estimated that three-quarters of all Americans had access to the Internet [10]. In 2003, the National Cancer Institute estimated that in the prior year, a third of all Americans used the Internet to search for health-related information at least monthly and 
two-thirds used the Internet for this purpose at least once a year [11]. This widespread use of online information-seeking predated the rise of interactive content and social networking (e.g., Facebook, Twitter) on the Internet, frequently referred to as "Web 2.0" $[12,13]$. Web 2.0 has changed the way that people can use the Internet to access health-related information [14]. In this era of Web 2.0, use of the Internet to seek information on vaccines is common $[15,16]$. The widespread use of rapidly updated, interactive content has not only increased the potential audience base for Internet based information, it has made it impossible to regulate the information that reaches parents searching for vaccine information. Much of the Internet-based vaccine information that reaches parents contains antivaccine content [17-21], and this is often couched in scientific-sounding language to lend an air of legitimacy to the antivaccine messaging [21].

While it is important to understand which sources are currently used to gather information about vaccines, there is a need for historical context for these findings. For example, we need to understand whether the high level of Internet use regarding vaccine information is a new phenomenon due to the existence of Web 2.0 or if it was common prior to the advent of Web 2.0. Additionally, changes in demographics of those seeking vaccine information over the Internet are important to understand so that future interventions can be appropriately targeted. This study examines the parental attitudes and beliefs associated with Internet use as a source of vaccine information among participants in a survey regarding vaccine exemptions conducted in the pre-Web 2.0 era [22].

\section{Materials and Methods}

This study is a secondary analysis of data collected for a previous study to examine refusal of vaccines among children enrolled in elementary schools in four US states. Detailed study procedures and methods are published elsewhere [22].

2.1. Target Population and Sample Participants. From an earlier study of school nurses on the topic of vaccine exemptions [23], 1,000 schools were sampled across four states (Colorado, Massachusetts, Missouri, and Washington), including the 150 schools with the highest exemption rates per state, 50 schools with the lowest exemption rates per state, and 50 schools randomly selected from the remaining schools in each state. States were selected on their proportion of exemptions compared to other states (high, medium, and low) [23]. Of these 1,000 schools, 112 were selected for a later study of factors related to vaccine exemptions [22], based on having at least five students with exemptions to vaccination. Up to thirteen children with exemptions were randomly selected from each of the 112 schools, resulting in a total of 815 children selected as cases (children with exemptions for 1 or more vaccines). For each case, two fully vaccinated children were randomly selected from the same school and grade to be controls.

This study was approved by the Institutional Review Board at Johns Hopkins Bloomberg School of Public Health.
2.2. Survey Procedure. Survey packets, including a disclosure letter to indicate consent to participate, were mailed to parents of the selected children by school nurses and school personnel who were trained by the study team. Surveys were returned by mail to the study team at Johns Hopkins. Surveys sent to parents in Massachusetts were mailed in February 2002, and surveys sent to parents in Colorado, Missouri, and Washington were mailed in February 2003.

Surveys mailed to the parents of exempt children contained exemption-specific questions to distinguish surveys completed by parents of children with exemptions from surveys completed by parents of fully vaccinated children; this allowed the researchers to identify students with exemptions without collecting any identifying information.

2.3. Survey Content. Parents of exempt children were asked to confirm that their child was missing at least one vaccine required by their school, the reason for claiming the exemption, and for medical exemptions, they were asked for the medical contraindication. Parents were excluded from data analysis if their child was listed by the school as exempt but they indicated that their child was fully vaccinated or if their child had a valid medical exemption.

Parents were asked to identify which of 16 sources they had used in the past to obtain information about vaccines (healthcare provider's advice; Vaccine Information Statements; professional organizations; alternative healthcare providers; parents and friends; religious leaders and organizations; media; Internet; local or state health departments; US Centers for Disease Control and Prevention; US Food and Drug Administration; vaccine companies; pharmacists; National Vaccine Information Center; Dissatisfied Parents Together; National Academy of Sciences, Institute of Medicine). For each of these 16 vaccine information sources, respondents were also asked, indicate their perceptions of the quality of the source using a 5-point Likert scale ("extremely poor source" to "excellent source"). Parents were free to interpret these responses through their own perceptions of source quality. The survey did not provide specific guidance regarding what was meant by the terms "poor," "excellent", and so forth.

For ten diseases with elementary school vaccination requirements (diphtheria, pertussis, tetanus, measles, mumps, rubella, polio, Haemophilus influenzae type b, varicella, and hepatitis B), respondents were asked to use 5-point Likert scales to identify their perceptions of (a) the likelihood that an unimmunized child in the United States would get one of these diseases within the next ten years, (b) the severity if an 8-year old were to get one of these diseases, (c) the effectiveness of vaccines in protecting against these diseases, and (d) the safety of the vaccines against these diseases.

Beliefs about immunization, and trust in healthcare professionals and the government, were measured using series of 14 questions (immunization beliefs), 11 questions (healthcare professionals), and 6 questions (government), assessed using 5-point Likert scales. Beliefs on who benefits from vaccination (the child, the community, doctors, the government, companies that make vaccines) were assessed 
using individual 5-point Likert scales ("not at all" to a "great deal").

Categorical demographic data were collected on age, highest level of education completed, gross household income, and race or ethnicity. For analysis, demographic data were dichotomized, using median values for cutpoints (age: 40 years and younger versus 41 years and older; education: some college or less versus college graduate or higher; income: less than $\$ 70,000$ versus $\$ 70,000$ and higher; race: white versus all other race/ethnicity categories). Surveys took approximately 30 minutes to complete.

2.4. Data Analysis. The main analysis conducted with data from this survey [22] was a case-control analysis examining factors related to vaccine exemptions. The analysis presented here is an examination of knowledge, attitudes, beliefs, and practices related to vaccination among parents classified by whether they reported using the Internet to seek information on vaccines or not.

For Likert scales assessing the quality of vaccine information sources, immunization beliefs, and who benefits from vaccination, results were dichotomized, using the two highest level responses (e.g., "strongly agree" and "agree") compared to the other three lower responses.

Questions about disease susceptibility and severity, vaccine protectiveness and safety, and trust in healthcare professionals and government were summarized by calculating the mean score for each category's Likert scale. For disease susceptibility and severity and vaccine protectiveness and safety, one summary score was generated for each category, averaging over all 10 listed antigens and diseases. For questions of trust, one summary score was generated each for healthcare professionals and government, by averaging over the total questions (11 and 6, resp.) for each category. Each of these summary measures was dichotomized by comparing the lowest quartile of scores to all higher scores.

Logistic regression models were used to compare differences in demographic characteristics, beliefs about the quality of information sources, immunization key beliefs, who benefits from vaccination and perceptions about disease susceptibility and severity, vaccine protectiveness and safety, and trust in healthcare providers and government between respondents who used the Internet as a source of vaccine information and respondents who did not use the Internet as a source of vaccine information. Unadjusted analyses generating odds ratios (OR) and 95\% confidence intervals (CI) and adjusted analyses, including the presence or absence of any vaccine exemption as a covariate, generating adjusted odds ratios (aOR) with 95\% CI were conducted. Data were analyzed using SAS version 9.2 (SAS Institute Inc., Cary, NC).

\section{Results}

Surveys were returned by 1367 (56.1\%) of the 2435 parents of selected children, including 391 (48.6\%) of 805 parents of children with exemptions and $976(59.9 \%)$ of 1630 parents of fully vaccinated children. Of the 391 parents of children that were identified by their school as having an exemption to one or more vaccines, 114 were excluded from analysis; 86 indicated that their child was fully vaccinated and 28 respondents provided valid medical contraindications to vaccination. The remaining 277 parents of children with nonmedical exemptions, as well as all 976 parents of fully vaccinated children, were included in the analysis [22].

The majority of respondents $(n=997,79.6 \%)$ reported using between 2 and 6 sources for information on vaccines, while few reported using only a single information source $(n=55,4.4 \%)$. The most commonly used source of vaccine information was the child's healthcare provider $(n=$ $1149,91.7 \%$ ), followed by Vaccine Information Statements (printed materials from healthcare providers) $(n=1052$, $84.0 \%)$ and parents/friends $(n=674,53.8 \%)$. Six vaccine information sources were identified by approximately threequarters or more of respondents as good or excellent sources of information, including healthcare provider's advice $(n=$ 1004, 81.8\%) and the US Centers for Disease Control and Prevention and the National Immunization Program $(n=$ 911, 81.6\%). Among all respondents, 39.9\% $(n=425)$ reported that they view the Internet as a good or excellent source of vaccine information. Overall, 249 respondents (19.9\%) reported using the Internet as a source of vaccine information (hereafter referred to as "Internet users"; the remaining 1,004 respondents who reported not using the Internet as a source of vaccine information are hereafter referred to as "Non-Internet users").

Internet users were more likely to have at least a college degree (aOR, 1.49; 95\% CI, 1.12-2.00) and have a gross annual household income of $\$ 70,000$ or higher (aOR, 1.41; 95\% CI, 1.04-1.91). There were no significant differences in parental age, race/ethnicity, or choice of child's primary healthcare provider between Internet users and non-Internet users (Table 2). Internet users were more likely to have a child with an exemption to at least one vaccine than non-Internet users (OR, 3.53, 95\% CI, 2.61-4.76) (Table 2).

Internet users were significantly more likely than parents who did not use the Internet to believe that the National Vaccine Information Center was a good or excellent source of vaccine information (aOR, 1.69, 95\% CI, 1.12-2.55). The National Vaccine Information Center was previously known as Dissatisfied Parents Together, which was also included as an information source of interest in the survey; there was no difference in the perception of Dissatisfied Parents Together across Internet user category. Internet users were also more likely to regard alternative healthcare providers (aOR, 1.55 ; 95\% CI, 1.12-2.14) as a good or excellent source of information. Internet users were less likely than non-Internet users to consider the following good or excellent sources of vaccine information: healthcare providers (aOR, 0.59; 95\% CI, 0.42-0.85), Vaccine Information Statements (aOR, 0.49; 95\% CI, 0.35-0.69), professional organizations (aOR, 0.56; 95\% CI, 0.39-0.80), local or state health departments (aOR, 0.60 ; 95\% CI, 0.43-0.84), and the CDC (aOR, 0.57; 95\% CI, $0.39-0.83$ ) (Table 1).

Internet users more commonly held key beliefs about vaccines that are not supported by scientific research on vaccines than non-Internet users (Table 3 ). Internet users 
TABLE 1: Perceptions of vaccine information sources among parents who did or did not use the Internet for vaccine information.

Internet used as a source of vaccine information

Information source

$$
\text { Yes }(N=249)^{*} \quad \text { No }(N=1,004)^{*} \quad \text { Unadjusted OR }(95 \% \text { CI }) \text { Adjusted } \mathrm{OR}^{\dagger}(95 \% \mathrm{CI})
$$

Good or excellent source Good or excellent source

\begin{tabular}{|c|c|c|c|c|}
\hline & $N(\%)^{\ddagger}$ & $N(\%)^{\ddagger}$ & & \\
\hline $\begin{array}{l}\text { Printed materials from } \\
\text { health-care provider (Vaccine } \\
\text { Information Statements) }\end{array}$ & $141(58.0 \%)$ & $785(80.9 \%)$ & $0.33(0.24-0.44)$ & $0.49(0.35-0.69)$ \\
\hline $\begin{array}{l}\text { Professional organizations, such } \\
\text { as doctors/nurses' associations }\end{array}$ & $130(60.5 \%)$ & $691(80.0 \%)$ & $0.38(0.28-0.53)$ & $0.56(0.39-0.80)$ \\
\hline $\begin{array}{l}\text { US Centers for Disease Control } \\
\text { and Prevention (CDC) and the } \\
\text { National Immunization Program }\end{array}$ & $154(68.4 \%)$ & $757(85.0 \%)$ & $0.38(0.27-0.54)$ & $0.57(0.39-0.83)$ \\
\hline Health-care provider's advice & $170(68.8 \%)$ & $834(85.1 \%)$ & $0.39(0.28-0.53)$ & $0.59(0.42-0.85)$ \\
\hline Local or state health departments & $140(59.6 \%)$ & $729(78.0 \%)$ & $0.42(0.31-0.56)$ & $0.60(0.43-0.84)$ \\
\hline $\begin{array}{l}\text { Religious leaders and } \\
\text { organizations }\end{array}$ & $13(6.5 \%)$ & $65(8.0 \%)$ & $0.79(0.43-1.47)$ & $0.81(0.43-1.52)$ \\
\hline $\begin{array}{l}\text { US Food and Drug } \\
\text { Administration (FDA) }\end{array}$ & $105(50.2 \%)$ & $526(61.6 \%)$ & $0.63(0.46-0.85)$ & $0.83(0.60-1.15)$ \\
\hline Pharmacists & $107(48.9 \%)$ & $504(56.8 \%)$ & $0.73(0.54-0.98)$ & $0.97(0.71-1.33)$ \\
\hline Vaccine companies & $54(23.2 \%)$ & $251(28.8 \%)$ & $0.75(0.53-1.05)$ & $0.98(0.69-1.40)$ \\
\hline Parents/Friends & $82(34.0 \%)$ & $300(32.3 \%)$ & $1.08(0.80-1.46)$ & $1.03(0.76-1.41)$ \\
\hline $\begin{array}{l}\text { Media (TV, radio, newspapers, } \\
\text { books, magazines) }\end{array}$ & $77(32.6 \%)$ & $273(29.6 \%)$ & $1.15(0.85-1.57)$ & $1.18(0.86-1.62)$ \\
\hline $\begin{array}{l}\text { National Academy of Sciences, } \\
\text { Institute of Medicine (IOM) }\end{array}$ & $101(66.0 \%)$ & $432(64.5 \%)$ & $1.07(0.74-1.55)$ & $1.22(0.83-1.80)$ \\
\hline $\begin{array}{l}\text { Dissatisfied Parents Together } \\
\text { (DPT) }\end{array}$ & $46(30.3 \%)$ & $127(19.7 \%)$ & $1.77(1.19-2.64)$ & $1.22(0.79-1.87)$ \\
\hline $\begin{array}{l}\text { Alternative health care providers, } \\
\text { such as chiropractors or } \\
\text { acupuncturists }\end{array}$ & $104(50.0 \%)$ & $271(33.5 \%)$ & $1.98(1.46-2.70)$ & $1.55(1.12-2.14)$ \\
\hline $\begin{array}{l}\text { National Vaccine Information } \\
\text { Center }\end{array}$ & $152(78.0 \%)$ & $600(76.1 \%)$ & $1.12(0.76-1.61)$ & $1.69(1.12-2.55)$ \\
\hline Internet & $134(56.3 \%)$ & $291(35.2 \%)$ & $2.37(1.77-3.18)$ & $2.45(1.80-3.32)$ \\
\hline
\end{tabular}

were less likely than non-Internet users to believe that vaccines strengthen the immune system $(\mathrm{aOR}, 0.65 ; 95 \% \mathrm{CI}$, 0.46-0.92) and more likely to believe that children get more immunizations than are good for them (aOR, 2.88; 95\% CI, 2.03-4.10), healthy children do not need immunizations (aOR, 2.06; 95\% CI, 1.28-3.31), immunizations do more harm than good (aOR, 2.47; 95\% CI, 1.60-3.81), and that a child's immune system could be weakened by too many immunizations (aOR, 1.74; 95\% CI, 1.25-2.43).

Internet users were also significantly more likely to be opposed to immunization requirements because immunization requirements go against the freedom of choice (aOR, 2.36; 95\% CI, 1.64-3.39) and because parents know what is best for their children (aOR, 2.68; 95\% CI, 1.754.09) than non-Internet users. Additionally, Internet users were less likely to recognize the benefits of immunization for their child (aOR, 0.39; 95\% CI, 0.25-0.59) as well as the community benefits from vaccination (for the child's family, playmates, and neighbors) (aOR, 0.53; 95\% CI, 0.36$0.76)$. Relatedly, these parents also had lower perceptions of disease susceptibility, vaccine protectiveness and vaccine safety (Table 4). No significant differences were observed for trust in government or trust in healthcare providers by Internet vaccine information seeking behaviors.

\section{Discussion}

This analysis provides a historical context for beliefs about vaccine effectiveness and safety, among parents surveyed 
TABLE 2: Demographic characteristics as predictors for Internet use as a source of vaccine information among parents of school aged children.

\begin{tabular}{|c|c|c|c|c|}
\hline \multirow[b]{2}{*}{ Characteristics } & \multicolumn{3}{|c|}{ Internet used as a source of vaccine information } & \multirow[b]{2}{*}{$\begin{array}{l}\text { Adjusted } \mathrm{OR}^{*} \\
\quad(95 \% \mathrm{CI})\end{array}$} \\
\hline & $\begin{array}{c}\text { Yes }(N=249)^{\dagger \dagger} \\
N(\%)\end{array}$ & $\begin{array}{c}\text { No }(N=1,004)^{\dagger \dagger} \\
N(\%)\end{array}$ & $\begin{array}{l}\text { Unadjusted OR } \\
\quad(95 \% \mathrm{CI})\end{array}$ & \\
\hline Older parent age $^{\dagger}$ & $80(32.7 \%)$ & $378(38.3 \%)$ & $0.78(0.58-1.05)$ & $0.72(0.53-0.97)$ \\
\hline Higher parent education $^{\ddagger}$ & $145(58.2 \%)$ & $465(46.3 \%)$ & $1.62(1.22-2.14)$ & $1.49(1.12-2.00)$ \\
\hline Higher household income $e^{\S}$ & $105(47.5 \%)$ & $346(39.5 \%)$ & $1.39(1.03-1.87)$ & $1.41(1.04-1.91)$ \\
\hline Parent race ${ }^{\|}$ & $211(92.1 \%)$ & $883(92.7 \%)$ & $0.93(0.54-1.59)$ & $0.78(0.45-1.37)$ \\
\hline $\begin{array}{l}\text { Child's primary healthcare } \\
\text { provider }\end{array}$ & $39(15.9 \%)$ & $89(9.0 \%)$ & $1.91(1.27-2.86)$ & $1.27(0.83-1.96)$ \\
\hline $\begin{array}{l}\text { Child is exempt for one or more } \\
\text { vaccines** }\end{array}$ & $105(42.2 \%)$ & $172(17.1 \%)$ & $3.53(2.61-4.76)$ & N/A \\
\hline
\end{tabular}

*Adjusted for exemption status.

${ }^{\dagger}$ Parent age is above the median (41 years or older) compared to younger.

‡Parent's education level is above the median (college graduate or higher) compared to lower education levels.

$\S$ Total household income is above the median ( $\$ 70,000$ or higher) compared to lower household income.

"Parent's race is white compared to all other races/ethnicities.

"Child's primary healthcare provider is not a doctor (nurse, physician's assistant, chiropractor, homeopathic doctor, or other) compared to doctor/physician.

** Child has nonmedical exemption for one or more vaccine compared to fully vaccinated; odds ratios adjusted by exemption status or stratified on exemption status could not be calculated.

${ }^{\dagger \dagger}$ Counts presented represent the count of nonmissing data, and the corresponding percentage is the percent of respondents in each Internet usage group with nonmissing data that indicated that a given information source was a "Good or excellent source." Missing data were not consistent over information source. Odds ratios are calculated based on nonmissing results through unadjusted and adjusted logistic regression.

prior to the widespread utilization of interactive Internet content and social networking ("Web 2.0"). We found that parents who reported using the Internet to obtain information about vaccines were less likely to agree with accepted tenets of vaccine science, less likely to agree that children need or benefit from vaccines, and more likely to have obtained nonmedical exemptions from vaccination for their children. While there have been recent studies about parental attitudes on vaccination $[15,16,24,25]$, it has been difficult to gauge whether these current attitudes have only recently risen to the observed levels or if current findings are highlighting issues that have been more constant over the years and across changing technology platforms, such as the increased use of interactive content.

This analysis indicates a relationship between Internet use and an acceptance of alternative views to traditional medicine about vaccination that predates the rise of Web 2.0 interactive content on the Internet. Approximately 37\% of parents who had children with exemptions reported using the Internet for vaccine information in 2002-3, when this survey was conducted. A recent survey of parents in Utah seeking exemptions for their children documented Internet use for vaccine information of only $43 \%$ [26].

Among respondents in this survey, parents who used the Internet as a source of vaccine information were more likely to view the advice of an alternative healthcare provider, such as a chiropractor or acupuncturist, as an accurate source of vaccine information. They were also more likely to view the National Vaccine Information Center, a nonprofit organization that questions the safety of vaccination, as an accurate source. Interestingly, there was less support for Dissatisfied Parents Together, the precursor to the National Vaccine Information Center. As Salmon et al. describe, this may be due to the more neutral, less advocacy-oriented name of the
National Vaccine Information Center, relative to Dissatisfied Parents Together [22]. Internet users were significantly less likely to view healthcare providers, professional organizations, and governmental health departments as an accurate source of information. This suggests that the Internet was used more often by parents seeking alternative opinions to traditional medicine than by parents who trust their child's physician as a source of information. A 2006 study in Oregon documented higher rates of use of naturopathic providers among vaccine exemptors than non-exemptors, both for parents themselves (49\% versus 13\%) and for their children (25\% versus $2 \%$ ) [27]. That study was conducted just a few years after the data collection for the analysis presented here, and there is further need to examine these healthcare trust and usage patterns over time.

An important finding in this analysis is that parents who use the Internet for vaccine information have lower perceptions of disease susceptibility. This reflects a general decrease in the public's concern over vaccine-preventable diseases as they have become less common in the United States $[28,29]$, but also suggests that a lack of concern over preventable childhood diseases has motivated parents to seek information from additional sources. Parents who used the Internet for vaccine information were also significantly more likely to have low perceptions of vaccine safety and protectiveness. The parents who sought out vaccine information on the Internet in this study were more likely to be higher educated, have a higher household income, and be younger; these demographic patterns fit well with those associated with parents of children who have received none of the routinely recommended childhood vaccines [30].

While these data cannot establish causality for the associations, the information provides evidence supporting the potential for improving vaccine information content 
TABLE 3: Association of vaccination beliefs with Internet use as a source of vaccine information among parents of school aged children.

\begin{tabular}{|c|c|c|c|c|}
\hline \multirow[b]{2}{*}{ Key beliefs (agree or strongly agree) } & \multicolumn{2}{|c|}{ Internet used as a source of vaccine information } & \multirow[b]{2}{*}{$\begin{array}{l}\text { Unadjusted OR } \\
\quad(95 \% \mathrm{CI})\end{array}$} & \multirow[b]{2}{*}{$\begin{array}{l}\text { Adjusted OR* } \\
\quad(95 \% \mathrm{CI})\end{array}$} \\
\hline & $\begin{array}{c}\text { Yes }(N=249) \\
N(\%)^{\dagger}\end{array}$ & $\begin{array}{c}\text { No }(N=1,004) \\
\quad N(\%)^{\dagger}\end{array}$ & & \\
\hline $\begin{array}{l}\text { Children should only be immunized against } \\
\text { serious diseases }\end{array}$ & $152(62.6 \%)$ & $577(60.4 \%)$ & $1.10(0.82-1.47)$ & $1.07(0.79-1.44)$ \\
\hline $\begin{array}{l}\text { Children get more immunizations than are } \\
\text { good for them }\end{array}$ & $139(59.9 \%)$ & $246(27.3 \%)$ & $3.97(2.94-5.37)$ & $2.88(2.03-4.10)$ \\
\hline $\begin{array}{l}\text { I am concerned that children's immune } \\
\text { system could be weakened by too many } \\
\text { immunizations }\end{array}$ & $140(61.1 \%)$ & $331(38.7 \%)$ & $2.50(1.85-3.37)$ & $1.74(1.25-2.43)$ \\
\hline $\begin{array}{l}\text { I am more likely to trust immunizations that } \\
\text { have been around for a while }\end{array}$ & $180(73.5 \%)$ & $765(78.6 \%)$ & $0.75(0.55-1.04)$ & $1.03(0.73-1.46)$ \\
\hline $\begin{array}{l}\text { Immunizations are one of the safest forms } \\
\text { of medicine ever developed }\end{array}$ & $61(26.3 \%)$ & $350(39.7 \%)$ & $0.54(0.39-0.75)$ & $0.73(0.52-1.03)$ \\
\hline $\begin{array}{l}\text { Immunizations are getting better and safer } \\
\text { all of the time, as a result of medical research }\end{array}$ & $107(46.5 \%)$ & $526(62.0 \%)$ & $0.53(0.40-0.71)$ & $0.75(0.54-1.03)$ \\
\hline Vaccines strengthen the immune system & $65(29.3 \%)$ & $358(46.0 \%)$ & $0.49(0.35-0.67)$ & $0.65(0.46-0.92)$ \\
\hline $\begin{array}{l}\text { It is better for a child to develop immunity } \\
\text { by getting sick than to get a vaccine }\end{array}$ & $68(29.8 \%)$ & $150(16.7 \%)$ & $2.12(1.52-2.96)$ & $1.31(0.90-1.91)$ \\
\hline $\begin{array}{l}\text { Healthy children do not need } \\
\text { immunizations }\end{array}$ & $43(17.6 \%)$ & $52(5.8 \%)$ & $3.75(2.43-5.77)$ & $2.06(1.28-3.31)$ \\
\hline Immunizations do more harm than good & $56(23.7 \%)$ & $66(7.0 \%)$ & $4.16(2.82-6.15)$ & $2.47(1.60-3.81)$ \\
\hline $\begin{array}{l}\text { I am opposed to immunization } \\
\text { requirements because they go against } \\
\text { freedom of choice }\end{array}$ & $90(36.6 \%)$ & $134(13.8 \%)$ & $3.61(2.63-4.95)$ & $2.36(1.64-3.39)$ \\
\hline $\begin{array}{l}\text { I am opposed to immunization } \\
\text { requirements because parents know what is } \\
\text { best for their children }\end{array}$ & $56(23.0 \%)$ & $64(6.5 \%)$ & $4.26(2.88-6.30)$ & $2.68(1.75-4.09)$ \\
\hline $\begin{array}{l}\text { Immunization requirements protect } \\
\text { children from getting diseases from } \\
\text { unimmunized children }\end{array}$ & $114(48.5 \%)$ & $690(74.8 \%)$ & $0.32(0.24-0.43)$ & $0.44(0.32-0.60)$ \\
\hline $\begin{array}{l}\text { Parents should be allowed to send their } \\
\text { children to school even if not vaccinated }\end{array}$ & $141(58.3 \%)$ & $286(30.2 \%)$ & $3.23(2.41-4.32)$ & $2.21(1.59-3.07)$ \\
\hline \multicolumn{5}{|l|}{$\begin{array}{l}\text { Who benefits from vaccination (moderate or } \\
\text { great deal of benefit) }\end{array}$} \\
\hline The child & $160(68.4 \%)$ & $849(90.2 \%)$ & $0.23(0.17-0.33)$ & $0.39(0.25-0.59)$ \\
\hline $\begin{array}{l}\text { The community-family, child's playmates, } \\
\text { people in the child's neighborhood }\end{array}$ & $152(65.0 \%)$ & $792(84.7 \%)$ & $0.33(0.24-0.46)$ & $0.53(0.36-0.76)$ \\
\hline The doctor & $120(56.1 \%)$ & $460(56.0 \%)$ & $1.00(0.74-1.36)$ & $1.06(0.78-1.45)$ \\
\hline The government & $117(58.8 \%)$ & $448(59.6 \%)$ & $0.97(0.70-1.33)$ & $0.98(0.70-1.35)$ \\
\hline The companies that make vaccines & $219(92.4 \%)$ & $807(89.7 \%)$ & $1.40(0.83-2.37)$ & $1.17(0.68-2.01)$ \\
\hline
\end{tabular}

* Adjusted for exemption status.

t Counts presented represent the count of non-missing data, and the corresponding percentage is the percent of respondents in each Internet usage group with non-missing data that indicated that a given information source was a "Good or excellent source." Missing data were not consistent over information source. Odds ratios are calculated based on non-missing results through unadjusted and adjusted logistic regression.

available on the Internet and other media. Moreover, the association between parental attitudes and use of the Internet as an information source can be bidirectional. The information on the Internet may influence parental attitude and behavior towards vaccines. On the other hand, distrust of vaccination and disapproval of immunization requirements may influence parents to use the Internet as an alternative source of information. The recently released http://www.vaccines.gov/ website provides a forum to promulgate science-based information on vaccines directly to parents and other vaccine consumers. This is one of a diverse set of credible resources on the topic of vaccines, which includes websites such as those from the Vaccine Education Center at Children's Hospital of Philadelphia [31], Parents of Kids with Infectious Diseases (PKIDs) [32], and the National Network for Immunization Information [33] which are good sources of readily accessible information on the safety and effectiveness of vaccines.

One limitation of this analysis is the potential for nonresponse bias. While there is no way to measure nonresponse bias in this study, it is likely that parents who felt strongly about immunization were more likely to return the survey than those with neutral opinions. Additionally, the response rate among parents of fully vaccinated children was 
TABLE 4: Association of disease, vaccine, and trust constructs with Internet use as a source of vaccine information among parents of school aged children.

\begin{tabular}{|c|c|c|c|c|}
\hline \multirow{3}{*}{ Diseases and vaccines } & \multicolumn{3}{|c|}{ Internet used as a source of vaccine information } & \multirow{3}{*}{ Adjusted OR* $(95 \% \mathrm{CI})$} \\
\hline & Yes $(N=249)$ & No $(N=1,004)$ & Unadjusted OR (95\% CI) & \\
\hline & $\begin{array}{c}\text { Lowest quartile } \\
\qquad N(\%)^{\emptyset}\end{array}$ & $\begin{array}{c}\text { Lowest quartile } \\
\qquad N(\%)^{\emptyset}\end{array}$ & & \\
\hline Disease susceptibility $^{\dagger}$ & $108(43.9 \%)$ & $196(20.4 \%)$ & $3.05(2.27-4.11)$ & $2.08(1.49-2.90)$ \\
\hline Disease severity ${ }^{\ddagger}$ & $90(36.7 \%)$ & $227(23.1 \%)$ & $1.93(1.43-2.61)$ & $1.35(0.97-1.87)$ \\
\hline Vaccine protectiveness ${ }^{\S}$ & $100(41.0 \%)$ & $203(21.2 \%)$ & $2.58(1.92-3.48)$ & $1.83(1.32-2.53)$ \\
\hline Vaccine safety ${ }^{\prime \prime}$ & $98(41.0 \%)$ & $199(21.2 \%)$ & $2.58(1.91-3.48)$ & $1.66(1.18-2.35)$ \\
\hline Trust in healthcare & $103(41.9 \%)$ & $348(35.1 \%)$ & $1.34(1.00-1.78)$ & $1.25(0.93-1.68)$ \\
\hline Trust in government & $73(29.6 \%)$ & $236(24.1 \%)$ & $1.32(0.97-1.80)$ & $1.30(0.94-1.79)$ \\
\hline
\end{tabular}

* Adjusted for exemption status.

${ }^{\dagger}$ How likely an unimmunized child in the United States is to acquire vaccine-preventable diseases on a 5-point Likert scale (impossible to very likely)—mean for 10 diseases.

${ }^{\ddagger}$ How serious it would be if an 8-year-old child acquired vaccine-preventable diseases on a 5-point Likert scale (not at all serious to very serious) -mean for 10 diseases.

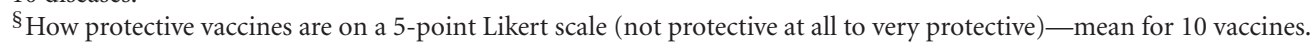

"How safe children's vaccines are on a 5-point Likert scale (very unsafe to very safe)—mean for 10 vaccines.

"Counts presented represent the count of non-missing data, and the corresponding percentage is the percent of respondents in each Internet usage group with non-missing data that indicated that a given information source was a "Good or excellent source." Missing data were not consistent over information source. Odds ratios are calculated based on non-missing results through unadjusted and adjusted logistic regression.

higher than the response rate among parents of children with exemptions, which could affect the results if factors influencing Internet use differ between these two groups. Another limitation of this study is that information on schools was not collected, to maintain confidentiality. This prevented accounting for similarities of respondents within schools within this analysis. While this would not be likely to influence the overall effect estimates, it could have implications when calculating the precision of these estimates.

These data were collected before the rise of interactive information sources and social networking sites, and so serve primarily as a benchmark for comparing vaccine attitudes, beliefs and practices in future studies. As information has become easier to find on the Internet, it is likely that parents who use the Internet frequently have encountered vaccine information on the Internet, whether they intended to or not. Therefore, data being collected and analyzed now that simply asks about sources of vaccine information have the potential to miss parents who actively seek out information on the Internet $[24,25]$. However, it is important to understand the characteristics of parents who actively seek information on the Internet, as these parents may have a higher likelihood of being influenced by Internet messaging. The data presented here provide information on parental attitudes and beliefs associated with parents who likely sought out vaccine information on the Internet, and provide a baseline on parental Internet use for vaccine information before the expansion of new media, interactive information sources, and social networking sites.

\section{Conclusions}

The results of this analysis have implications for the role of the Internet in vaccine communication. Because Internet use and nonmedical exemptions are significantly related, it is necessary for the content of Internet-based vaccine information to best target the appropriate audiences and to have the flexibility in presentation formats to meet the needs of all types of consumers.

\section{References}

[1] "Impact of vaccines universally recommended for childrenUnited States, 1990-1998," Morbidity and Mortality Weekly Report (MMWR), vol. 48, no. 12, pp. 243-248.

[2] "Ten great public health achievements-United States, 19001999," Morbidity and Mortality Weekly Report (MMWR), vol. 48, no. 12, pp. 241-243.

[3] S. W. Roush, T. V. Murphy, M. M. Basket et al., "Historical comparisons of morbidity and mortality for vaccinepreventable diseases in the United States," Journal of the American Medical Association, vol. 298, no. 18, pp. 2155-2163, 2007.

[4] Centers for Disease Control and Prevention, "National and state vaccination coverage among children aged 19-35 months-United States, 2010," Morbidity and Mortality Weekly Report (MMWR), vol. 60, no. 34, pp. 1157-1163, 2011.

[5] W. A. Orenstein and A. R. Hinman, "The immunization system in the United States-the role of school immunization laws," Vaccine, vol. 17, supplement 3, pp. S19-S24, 1999.

[6] "National, state, and local area vaccination coverage among children aged 19-35 months-United States, 2009," Morbidity and Mortality Weekly Report (MMWR), vol. 59, no. 36, pp. 1171-1177, 2010.

[7] S. B. Omer, W. K. Y. Pan, N. A. Halsey et al., "Nonmedical exemptions to school immunization requirements: secular trends and association of state policies with pertussis incidence," Journal of the American Medical Association, vol. 296, no. 14, pp. 1757-1763, 2006.

[8] S. B. Omer, K. S. Enger, L. H. Moulton, N. A. Halsey, S. Stokley, and D. A. Salmon, "Geographic clustering of nonmedical exemptions to school immunization requirements and 
associations with geographic clustering of pertussis," American Journal of Epidemiology, vol. 168, no. 12, pp. 1389-1396, 2008.

[9] A. Kennedy, J. Glasser, V. Covello, and D. Gust, "Development of vaccine risk communication messages using risk comparisons and mathematical modeling," Journal of Health Communication, vol. 13, no. 8, pp. 793-807, 2008.

[10] Nielsen//NetRatings, "Three out of four Americans have access to the Internet, according to Nielsen//NetRatings," March 18 2004, http://www.nielsen-online.com/pr/pr_040 318.pdf.

[11] National Cancer Institute, "HINTS: Questiondetails," 2003, http://hints.cancer.gov/question-details.aspx?dataset=2003\& qid $=772 \&$ qdid $=877$.

[12] P. Graham, Web 2.0, November 2005, http://www.paulgraham .com/web20.html.

[13] J. Musser and T. O'Reilly, “O'Reilly radar report: Web 2.0 principles and best practices," Sebastopol, CA: O’Reilly Media, 2006.

[14] H. O. Witteman and B. J. Zikmund-Fisher, "The defining characteristics of Web 2.0 and their potential influence in the online vaccination debate," Vaccine, vol. 30 , no. 25, pp. 3734 3740, 2012.

[15] A.-L. McRee, P. L. Reiter, and N. T. Brewer, "Parents' internet use for information about HPV vaccine," Vaccine, vol. 30, no. 25, pp. 3757-3762, 2012.

[16] P. Robichaud, S. Hawken, L. Beard et al., "Vaccine-critical videos on YouTube and their impact on medical students' attitudes about seasonal influenza immunization: a pre and post study," Vaccine, vol. 30, no. 25, pp. 3763-3770, 2012.

[17] S. J. Bean, "Emerging and continuing trends in vaccine opposition website content," Vaccine, vol. 29, no. 10, pp. 18741880, 2011.

[18] P. Davies, S. Chapman, and J. Leask, "Antivaccination activists on the world wide web," Archives of Disease in Childhood, vol. 87, no. 1, pp. 22-25, 2002.

[19] R. M. Wolfe and L. K. Sharp, "Vaccination or immunization? The impact of search terms on the internet," Journal of Health Communication, vol. 10, no. 6, pp. 537-551, 2005.

[20] R. M. Wolfe, L. K. Sharp, and M. S. Lipsky, "Content and design attributes of antivaccination web sites," Journal of the American Medical Association, vol. 287, no. 24, pp. 3245-3248, 2002.

[21] A. Kata, "Anti-vaccine activists, Web 2.0, and the postmodern paradigm - an overview of tactics and tropes used online by the anti-vaccination movement," Vaccine, vol. 30, no. 25, pp. 3778-3789, 2012.

[22] D. A. Salmon, L. H. Moulton, S. B. Omer, M. P. DeHart, S. Stokley, and N. A. Halsey, "Factors associated with refusal of childhood vaccines among parents of school-aged children: a case-control study," Archives of Pediatrics and Adolescent Medicine, vol. 159, no. 5, pp. 470-476, 2005.

[23] D. A. Salmon, L. H. Moulton, S. B. Omer et al., "Knowledge, attitudes, and beliefs of school nurses and personnel and associations with nonmedical immunization exemptions," Pediatrics, vol. 113, no. 6, pp. e552-e559, 2004.

[24] G. L. Freed, S. J. Clark, A. T. Butchart, D. C. Singer, and M. M. Davis, "Sources and perceived credibility of vaccinesafety information for parents," Pediatrics, vol. 127, no. 1, supplement 1, pp. S107-S112, 2011.

[25] A. Kennedy, M. Basket, and K. Sheedy, "Vaccine attitudes, concerns, and information sources reported by parents of young children: results from the 2009 HealthStyles survey," Pediatrics, vol. 127, no. 1, supplement 1, pp. S92-S99, 2011.
[26] K. E. Luthy, R. L. Beckstrand, and C. J. Meyers, "Common perceptions of parents requesting personal exemption from vaccination," The Journal of School Nursing. In press.

[27] J. A. Gaudino and S. Robison, "Risk factors associated with parents claiming personal-belief exemptions to school immunization requirements: community and other influences on more skeptical parents in Oregon, 2006," Vaccine, vol. 30, no. 6, pp. 1132-1142, 2012.

[28] R. T. Chen and B. Hibbs, "Vaccine safety: current and future challenges," Pediatric Annals, vol. 27, no. 7, pp. 445-455, 1998.

[29] B. G. Gellin, E. W. Maibach, and E. K. Marcuse, "Do parents understand immunizations? A national telephone survey," Pediatrics, vol. 106, no. 5, pp. 1097-1102, 2000.

[30] P. J. Smith, S. Y. Chu, and L. E. Barker, "Children who have received no vaccines: who are they and where do they live?" Pediatrics, vol. 114, no. 1, pp. 187-195, 2004.

[31] Vaccine Education Center, Welcome to the Vaccine Education Center, March 2012, http://www.chop.edu/service/vaccineeducation-center/home.html.

[32] “PKIDs-Home," 2012, http://www.pkids.org/.

[33] National Network for Immunization Information (NNii), 2010, http://www.immunizationinfo.org/. 


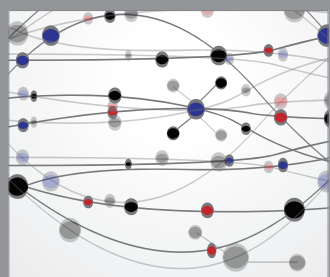

The Scientific World Journal
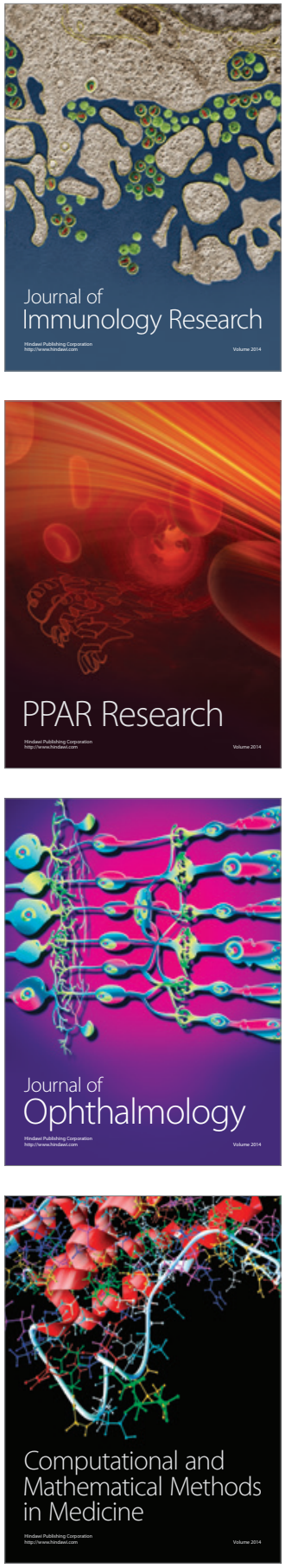

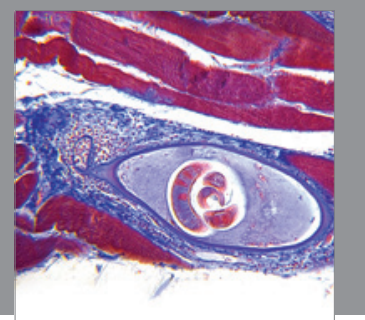

Gastroenterology

Research and Practice
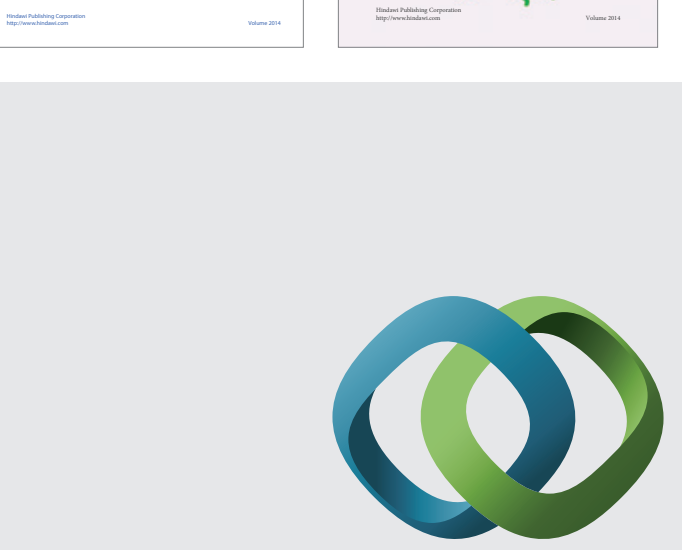

\section{Hindawi}

Submit your manuscripts at

http://www.hindawi.com
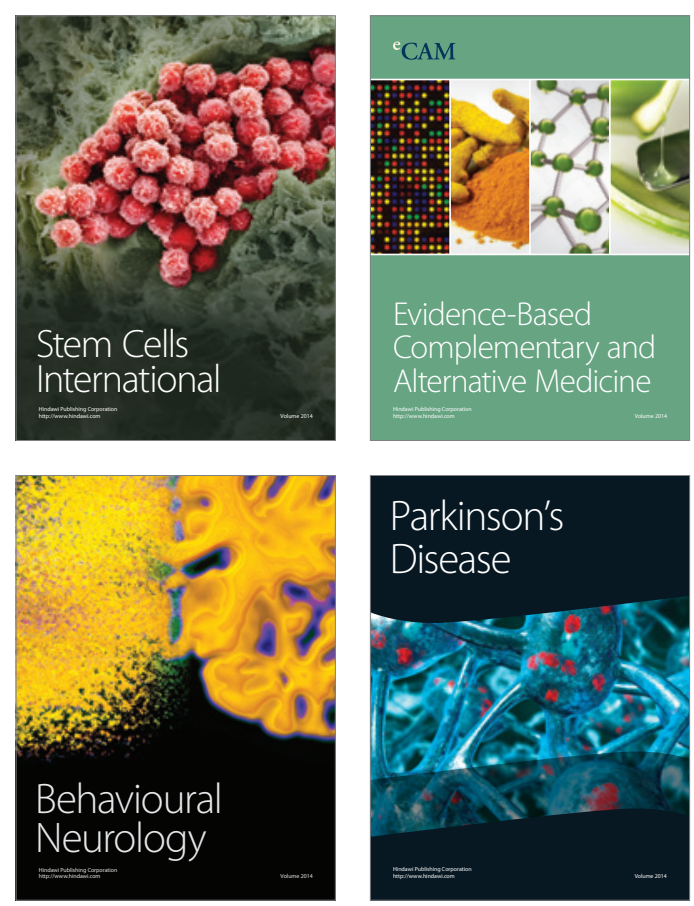

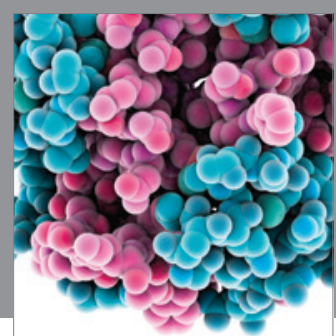

Journal of
Diabetes Research

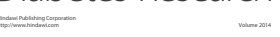

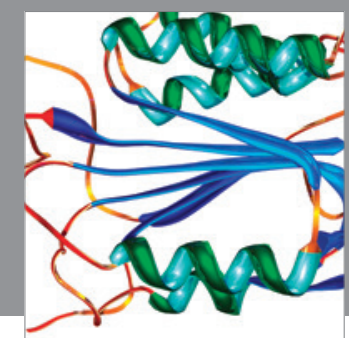

Disease Markers
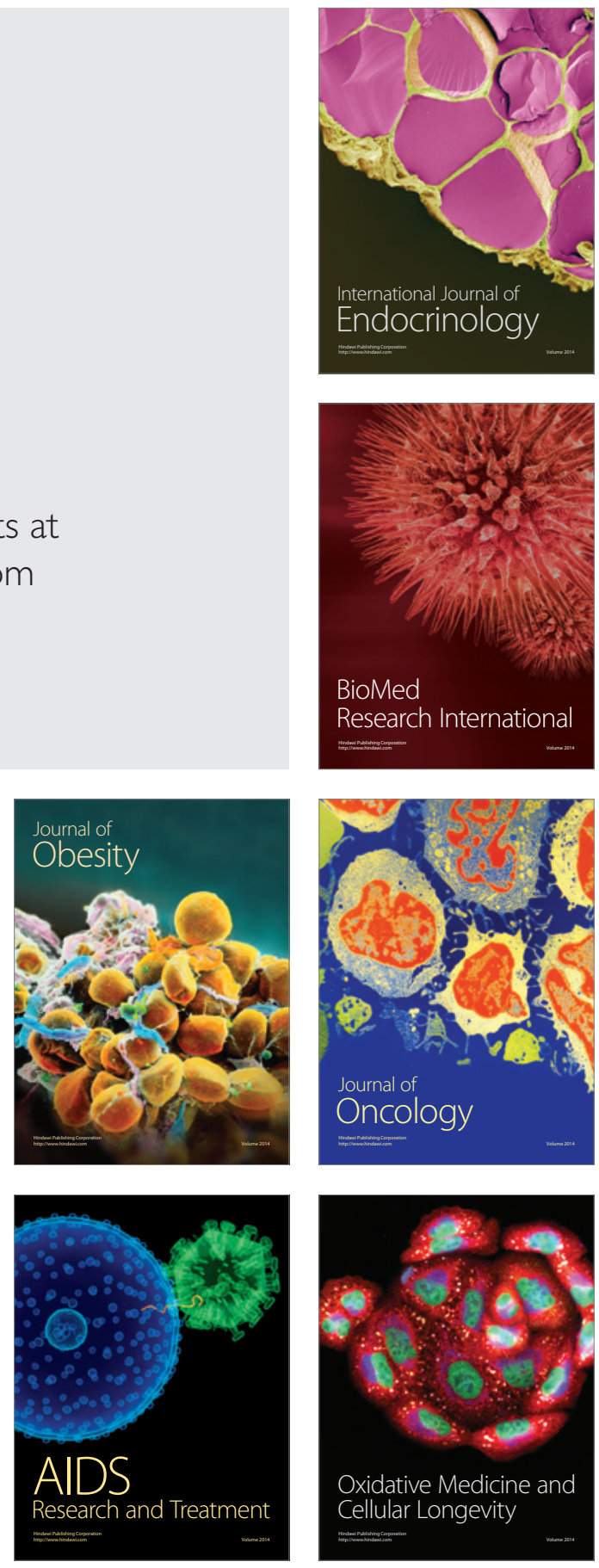